\title{
Rural general practice placements: alignment with the Australian Curriculum Framework for Junior Doctors
}

\section{Louise Young MPsychEd, PhD Associate Professor Rura Medical Education \\ Sarah L Larkins MB BS, MPH\&TM, PhD, Associate Professor. General Practice and Rural Medicine \\ Tarun K Sen Gupta MB BS, FACRRM, PhD, \\ Professor of Health Professional Education and Director of Medical Education}

Suzanne H McKenzie MB BS, MMedSci, FRACGP. Associate Professor and ead of General Practice and Rural Medicine

Rebecca J Evans BSptExSci(Hons) GradCertGovernancePolicy \&PubAff, PhD, Lecturer, General Practice and Rural Medicine

Michael J Crowe BSc(Mgmt), MIT, PhD Researcher

Elizabeth J Ware BSc, DipEd GradCertClinEd

Prevocational Medical Education Co-ordinator ${ }^{2}$

1 School of Medicine and Dentistry, James Cook University, Townsville, QLD.

2 Queensland Medical

Education and Training ClinEdQ, QLD Health, Mackay, QLD.

louise.young1@ jcu.edu.au

MJA 2013; 199: 787-790 doi: 10.5694/mjal3.10563

Editorial p 722 Research p 779 s part of the strategy to meet growing workforce demands in the Australian medical system, medical student numbers have been increased. In 2014, 3108 students are expected to graduate - up from 1335 in 2006. ${ }^{1}$ This growth is associated with challenges for education and training systems, including shortfalls in clinical placements and in adequate supervision for students and junior doctors. The growth also presents an opportunity to redress the current workforce maldistribution, but it is unrealistic to rely solely on a "trickle-out effect" that assumes increased numbers will lead to more medical graduates practising in traditionally underserved areas.

Consideration of alternative training settings provides an opportunity to explore socially accountable approaches in learning objectives and curricula, ${ }^{2,3}$ provision of highquality clinical experiences in underserved populations $s^{4-6}$ and expansion of training options in rural areas. To ensure that students and junior doctors currently training are appropriately equipped to practise in a range of underserved areas, a strategic approach among educators and training institutions is required, including expanding training options in areas that are outside the traditional vocational training rotations. ${ }^{7-10}$

Offering general practice placements for interns is an important strategy for avoiding the expected shortfall of clinical placements and supervisors in the hospital system. While medical schools and vocational training are already providing training experiences in underserved areas such as rural sites, it is timely to investigate the option of a rural general practice placement during the intern year. Such placements must ensure that experiential learning is aligned with outcomes expected from the Australian Curriculum Framework for Junior Doctors (ACFJD). The ACFJD was designed by an experienced group of clinicians who outlined the knowledge, skills and behaviours required of junior doctors in postgraduate years 1, 2 and above. Areas covered by the framework include clinical management, professionalism, communication, skills and procedures, and clinical symptoms, problems and conditions. All clinical placements for prevocational doctors in Australia must meet the standards outlined in this framework. We have reviewed the available literature regarding skills and competencies gained by junior doctors in rural general practice placements, with particular reference to the ACFJD competencies.

Recommendations from a recent Senate report ${ }^{11}$ identified the need for a review of current literature to identify and develop a strategy to address gaps in research and
Objectives: To review the available literature regarding skills and competencies gained by junior doctors in rural and regional general practice placements and their alignment with the Australian Curriculum Framework for Junior Doctors (ACFJD).

Study design: A comprehensive literature review using a three-phase process. Articles were initially identified from database searches in OvidSP and Scopus. Additional information was obtained after a hand search of contents pages from relevant journals and from reports, conference abstracts and grey literature. Documented skills and procedures were mapped against the competencies from the ACFJD.

Data sources: We analysed 36 relevant articles written in English and published during 1997-2011. Articles referring to learning outcomes for junior doctors training with rural general practitioners were included.

Data synthesis: Evidence was available of the advantages of junior doctor rural general practice placements in gaining advanced skills in the areas of communication and professionalism, as well as developing autonomy in clinical management and decision making. Less evidence was available regarding exposure to particular clinical conditions and development of specific clinical skills.

Conclusion: Rural and regional general practice placements for junior doctors are likely to comply with the ACFJD requirements and, further, provide excellent learning opportunities in several domains of the curriculum. However, there was little research published confirming learning outcomes for junior doctors in rural general practice settings.

knowledge affecting rural health service delivery (Recommendation 2). Although not a systematic review, our work provides a narrative review conducted in a systematic way. A recent publication ${ }^{12}$ stated that mixed methods reviews are an emerging field of research. The authors suggested that reviews in medicine using both quantitative and qualitative data should be considered within the scope of systematic reviews. Our literature review provides a starting point for documenting evidence related to rural training settings for junior doctors and the clinical skills they learn during a rural placement.

\section{Methods}

The review was undertaken in May 2011 using three different strategies. All strategies followed a similar sys- 


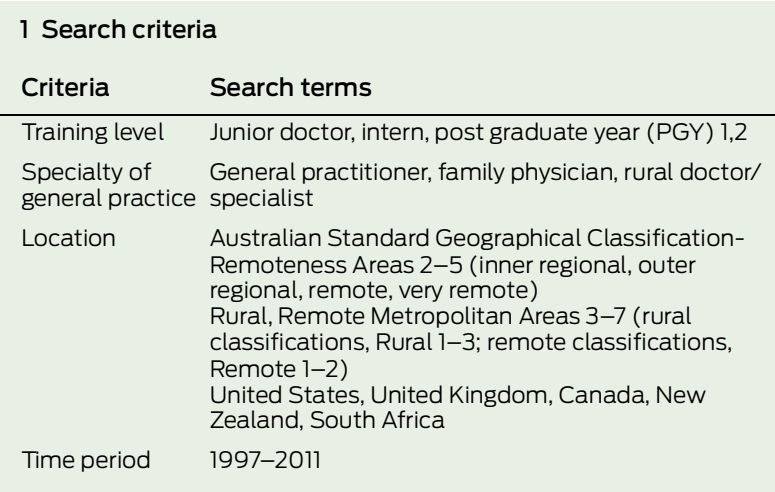

tematic approach using the search criteria outlined in Box 1. Initially, articles published in English that reported rural placements for junior doctors were identified from the OvidSP and Scopus databases. The search terms for rural included definitions that incorporated regional centres as well as more rural and remote locations. Articles were identified by keywords, subject heading, title or abstract using criteria outlined in Box 1. Reviewers systematically worked through all the articles and then collated the relevant content under one or more core competencies outlined in the ACFJD.

A poor initial return rate meant the search was reevaluated. Using the same criteria, we conducted a hand search of contents pages of relevant journals such as Medical Education, Academic Medicine, the Medical Journal of Australia and Australian Family Physician. Data were also sourced from reports, conference abstracts and grey literature available from government and other organisations (Box 2).

Articles reporting undergraduate and junior doctor outcomes in the same article were included, while articles reporting medical student outcomes were only included if they provided evidence of outcomes that would be transferable to junior doctors undertaking rural clinical placements. Articles were discarded if they focused on: topics outside the scope of this review; education and training needs of qualified general practitioners; general practice workforce or registrar issues, such as recruitment, retention, gender roles and training posts in rural hospitals; or undergraduate curricula or placements exclusively.

\section{Results}

The initial search strategy identified 389 articles from OvidSP, of which only two could be classified using the framework competencies, and 216 articles from Scopus, none of which were relevant to the framework. Eightynine papers were identified from the journals and 29 of these could be classified according to the framework competencies. Overall, 195 items were identified as potentially relevant. Of these, 36 articles and reports were included.

Publications ranged from 1997 to 2011. The highest number in any year was six in 2005. The countries most often included were Australia (17 articles or reports) and the United Kingdom (13). The most common research design used in the literature was qualitative (14 publications). This was followed by survey (9), retrospective

\section{Data sources for search}

Source

Australian

Government

State and territory

governments

General practice

training providers

Peak bodies

Non-Australian organisations

Reference lists

\section{Organisations}

Health Workforce Australia, Australian Institute of Health and Welfare, National Health Workforce Taskforce

Australian College of Rural and Remote Medicine, Royal Australian College of General Practitioners, Rural Doctors Association of Australia, General Practice Training program

United Kingdom General Medical Council, Royal College of Physicians and Surgeons of Canada, World Organisation of Family Doctors (WONCA)

Material discovered when reading articles, reports and other literature Confederation of Postgraduate Medical Education Councils, Australian

cohort (7) and opinion piece (6). Box 3 outlines these results, and a summary of the relevant literature is shown in Appendix 1 (online at mja.com.au).

From these publications, we report learning outcomes for junior doctors training with rural GPs, including only documented skills and procedures. As we used data that were already in the public domain, ethics approval was not required.

Most of the literature initially identified as potentially relevant provided evidence about skills gained by medical students or vocational trainees in rural general practice placements, or the distribution of GPs in Australia, patient characteristics and reasons for encounters across a range of geographical locations. There was little published research covering the range of skills or competencies gained by junior doctors on rural clinical placements, especially nontraditional placements such as rural private general practices. The 36 articles and reports we identified as relevant focused on the advantages of junior doctor rural general practice placements for gaining advanced skills in communication and professionalism, as well as for developing autonomy in clinical management and decision making. Benefits for academic performance were also noted. Less evidence was available regarding exposure to particular clinical conditions, awareness of the impact of continuity of care, the development of specific clinical skills and the impact on later academic performance.

\section{Advantages of rural placements}

\section{Academic performance}

Academic performance covered formal assessments and supervisor reviews during clinical placements. Two reviews investigated differences in academic performance between undergraduate and postgraduate medical students undertaking rural and remote placements in the UK or United States. ${ }^{13,14}$ Neither found any difference between the academic performance of those on rural or remote placements compared with their urban colleagues. The UK review ${ }^{14}$ stated it was a myth that a general practice placement could affect career or academic performance, ${ }^{15}$ while the US review ${ }^{13}$ found two studies showing students on rural placements performed no worse than those on urban placements. Their key finding was that students on rural placements did as well as, if not better than, their urban counterparts. 
In individual retrospective cohort studies from the US, ${ }^{16,17}$ Canada $^{18,19}$ and Australia, ${ }^{20,21}$ findings were similar. There was no significant difference in performance between students and junior doctors training in urban settings compared with those in rural and remote settings.

\section{Skills and procedures}

A survey of ambulatory patients in an outpatient department and general practice in a remote Queensland town found that the types of patients seen in the outpatient department and private general practices were similar. ${ }^{22}$ It concluded that in remote Queensland, private general practices and outpatient departments could provide complementary placements for junior doctors.

Several studies demonstrated benefits of rural general practice placements for junior doctors. These included the opportunity to follow patients from general practice to hospital and back to general practice to experience the impact of continuity of care; development of a greater degree of autonomy, responsibility and confidence; more opportunities for procedural skills training; development of more discrimination in prescribing and requesting tests; and less tiredness due to the nature of the working day compared with hospital placements. ${ }^{23-25}$ Results from the Prevocational General Practice Placements Program (PGPPP), in which junior doctors participate in a general practice placement for 10-12 weeks (including the option of general practice clinics in rural and remote locations and with Indigenous communities), were similar. Outcomes from this program have shown that junior doctors' procedural skills, communication skills and experience of continuity of care increase. $^{26-28}$

\section{Disadvantages of rural placements}

A number of potential problems with general practice placements were identified. These included a greater sense of isolation from peers; extra costs associated with rural and remote placements, such as travel and cost of living; more on-call weekends than their urban counterparts; limits on the professional and physical capacity of a general practice to provide consulting rooms and supervision; ${ }^{24}$ ensuring appropriate indemnity cover; provision of suitable housing; and establishment of suitable education and support infrastructure. From an organisational perspective, issues raised included indemnity cover for junior doctors, training doctors and feeder hospitals; provision of housing to include families; and establishing education infrastructure to support junior doctors equivalent to that available for urban junior doctors. ${ }^{23,25}$

\section{Alignment with the ACFJD competencies}

We mapped the clinical skills and procedures that junior doctors are able to practise during a rural general practice placement, identified in the literature, against the five domains within the ACFJD. Results are shown in Appendix 2 and search references in Appendix 1 (online at mja.com.au). A number of additional skills were also identified. The findings are summarised below.

\section{Professionalism}

Professionalism competencies had the highest number of learning topics and individual items described in the literature. ${ }^{15,29-33}$ All individual learning topics were covered except "Practitioner in difficulty", and nearly 50\% of ACFJD professionalism competency items were mentioned.

\section{Communication}

Communication was the next most commonly mentioned domain. A rural placement is often the first opportunity for junior doctors to deal with patients as distinct individuals rather than just focusing on their illnesses. ${ }^{15,29-33}$ It has been shown that junior doctors participating in a rural placement program developed improved communication, self-assertiveness, the ability to practise preventive care and continuity of care with their patients and an increased understanding of Indigenous patients. ${ }^{26-28}$

\section{Clinical management}

Compared with urban practice, the range of problems encountered in rural general practice is likely to be broader, and clinical management more comprehensive. The learning topics we identified included systems knowledge; continuity of care and enhanced understanding of the interface between primary and subsequent care; history and examination; public health, problem formulation, investigations, referral and consultation; and discharge planning. ${ }^{22,33}$

\section{Skills and procedures}

Two articles identifying skills and procedures could be mapped to the ACFJD. These covered intramuscular injections, ${ }^{31}$ endocervical swab or Pap smear, assisting in the operating theatre, surgical knots and simple wound suturing, local anaesthesia, simple skin lesion excision, mental health and ophthalmic procedures. ${ }^{32}$ A number of articles reported exposure to procedural skills generally but did not provide specific examples that could be mapped directly to the ACFJD. ${ }^{15,26,29,30,33}$

\section{Clinical problems and conditions}

Clinical problems and conditions were usually described only in general terms. Examples included seizure disorders, joint disorders, chest pain and cough, ${ }^{15}$ sexually transmitted infections, ${ }^{31,32}$ dermatological conditions, contraception, nutrition and metabolic conditions, depression, infectious diseases, domestic violence ${ }^{32}$ and addiction. ${ }^{32,33}$

A number of areas were not specifically covered by the ACFJD but were mentioned in the literature as likely learning topics covered by junior doctors in rural general practice placements. These included assisting with childbirth; providing vaccinations; primary health care in Indigenous communities; deeper understanding of health and illness; otitis media and otitis externa; the lymphatic system and enlarged nodes; men's health; medication and recognition of side effects and interactions; treating patients in context - both rural and Indigenous; and capacity for personal and professional growth. 


\section{Discussion}

The available literature highlights the benefits of general practice placements for junior doctors in terms of developing professionalism, building rapport and communication skills with patients, and gaining an understanding of patients in context. The opportunity to develop clinical responsibility and professional identity was reported, and resulted in a strong sense of satisfaction. Some articles reflected opportunities to practise clinical or procedural skills in rural general practice settings and highlighted the importance of these placements in understanding the interface between primary care and secondary or tertiary care systems.

While our review has identified rural general practice placements for junior doctors as excellent training opportunities aligned with many of the ACFJD competencies, there is a lack of credible research evidence identifying and documenting specific clinical skills and procedures. Much of this review relies on professional experience in reports and other non-peer-reviewed documents. It is likely that there is some underreporting of clinical rural general practice experiences, and the results reported may not be generalisable to all rural general practice placements. However, this strengthens the argument for more robust research into the educational value of internship posts in these settings at this point of the medical education continuum, and the barriers to creating them.

While relatively little research has been published confirming the value of non-urban general practice settings for intern and junior doctor learning, particularly against the competencies identified in the ACFJD, there is evidence of high-quality learning experiences and outcomes for placements in community and non-urban locations at the undergraduate medical student level and at vocational training level. ${ }^{21,22}$ There is also evidence of a wide range of clinical conditions managed, patient demographics and investigations occurring in rural general practices when compared with urban practices. ${ }^{34,35}$

Rural general practice placements have the potential to be as beneficial for junior doctors as hospital placements, and provide complementary learning experiences. ${ }^{10}$ As increasing numbers of medical graduates enter the health system, alternative placements to tertiary hospitals are required to provide high-quality clinical training while developing the aptitude, interest and skills of junior doctors for subsequent practice in areas of high unmet need. ${ }^{9}$

Many of the competencies identified in the ACFJD should be achievable in rural general practice placements, contingent on adequate supervision and mentoring. However, the placement must be of similar quality to more traditional placements, with facilities available for junior doctors to consult, learn, study and seek advice. Building the capacity of a small number of distributed teaching sites as teaching centres of excellence, resourced with adequate preceptor training and support, may be one way of furthering this agenda. ${ }^{35}$ Implementation of a rural general practice placement during the intern year is an important strategy for ameliorating expected training pressures in the health system while broadening the range of experiences available to junior doctors.
Acknowledgements: The work reported in this article was funded under the Research and Publication Initiative of Clinical Education and Training Queensland, Queensland Health. We thank Jade Taylor for assistance in the preparation of this manuscript Competing interests: No relevant disclosures.

1 Australian Government. Medical Training Review Panel: thirteenth report. Canberra: Department of Health and Ageing, 2010. http://www.health.gov.au/internet/main/publishing.nsf/Content/work-pubs-mtrp-13 (accessed Sep 2013).

2 Pálsdóttir B, Neusy AJ, Reed G. Building the evidence base: networking innovative socially accountable medical educational programs. Educ Health (Abingdon) 2008; 21: 177.

3 Hays R, Stokes J, Veitch J. A new socially responsible medical school for regional Australia. Educ Health (Abingdon) 2003; 16:14-21.

4 Wilkinson D, Laven G, Pratt N, Beilby J. Impact of undergraduate and postgraduate rural training, and medical school entry criteria on rural practice among Australian general practitioners: national study of 2414 doctors. Med Educ 2003; 37: 809-814.

5 Worley P, Martin A, Prideaux D, et al. Vocational career paths of graduate entry medical students at Flinders University: a comparison of rural, remote and tertiary tracks. Med J Aust 2008; 188: 177-178.

6 Blue AV, Chessman AW, Geesey ME, et al. Medical students' perceptions of rural practice following a rural clerkship. Fam Med 2004; 36: 336-340.

7 Murray RB, Wronski I. When the tide goes out: health workforce in rural, remote and Indigenous communities. Med J Aust 2006; 185: 37-38.

8 Strasser R. Training for rural practice. Lessons from Australia. Can Fam Physician 2001; 47: 2196-2198.

9 National Rural Health Alliance. Plan for a greater number of interns for rural, regional and remote settings in 2012 [policy document]. Canberra: NRHA, 2011. http://ruralhealth.org.au/document/plan-greater-number-interns-ruralregional-and-remote-settings-2012-0 (accessed Sep 2013).

10 Medical Board of Australia. Proposed registration standard for consultation. Melbourne: Australian Health Practitioner Regulation Agency, 2011. http://www.medicalboard.gov.au/documents/default.aspx?record= WD11\%2F5557\&dbid=AP\&chksum=s0qlaSmidn7UGjcpVn8C\%2Fw\%3D\%3D (accessed Sep 2013).

11 Australian Senate Community Affairs References Committee. The factors affecting the supply of health services and medical professionals in rural areas. Canberra: Australian Government, 2012. http://www.aph.gov.au/ Parliamentary_Business/Committees/Senate/Community_Affairs/Completed_inquiries/2010-13/rurhlth/report/ index (accessed Sep 2013)

12 Wallace J, Byrne C,Clark M. Making evidence more wanted: a systematic review of facilitators to enhance the uptake of evidence from systematic reviews and meta-analyses. Int J Evid Based Healthc 2012; 10: 338-346.

13 Barrett FA, Lipsky MS, Lutfiyya MN. The impact of rural training experiences on medical students: a critical review. Acad Med 2011; 86: 259-263.

14 ScallanS. Training for general practice in the foundation programme: lessons from the pre-registration house officer experience. Educ Prim Care 2005; 16: 256-264.

15 Cantillon P, MacDermott M. Interns in general practice: an evaluation of a training innovation. Galway: National University of Ireland, 2005. http://www.nuigalway.ie/general_practice/documents/interns_in_general_practice_an evaluation_of_a_training_innovation.pdf (accessed Nov 2013).

16 Schaver RW, SchieveD. Performance of medical students in a nontraditional rural clinical program, 1998-99 through 2003-04. Acad Med 2006; 81: 603-607.

17 WhiteCB, Thomas AM. Students assigned to community practices for their pediatric clerkship perform as well or better on written examinations as students assigned to academic medical centers. Teach Learn Med 2004; 16: 250-254.

18 Bianchi F, Stobbe K, Eva K. Comparing academic performance of medical students in distributed learning sites: the McMaster experience. Med Teach 2008; 30:67-71.

19 McKendry RJ, Busing N, Dauphinee DW, et al. Does the site of postgraduate family medicine training predict performance on summative examinations? A comparison of urban and remote programs. CMAJ 2000; 163: 708-711.

20 Sen Gupta TK, Hays RB, Kelly GD, Buettner PG. Are medical student results affected by allocation to different sites in a dispersed rural medical school? Rural Remote Health 2011; 11: 1511.

21 Worley P, Esterman A, Prideaux D. Cohort study of examination performance of undergraduate medical students learning in community settings. BMJ 2004; 328: 207-209.

22 Veitch PC, Wallace DA, Doolan T. A comparison of a hospital outpatients department and general practice in remote Queensland. Aust J Rural Health 1999; 7: 160-165.

23 Grace K, Bradford CJ. Community and general practice terms for prevocational junior medical officers: experience and development in South Australia and Western Australia. Med J Aust 2007; 186 (7 Suppl): S28-S30.

24 Mugford B, Martin A. Rural rotations for interns: a demonstration programme in South Australia. Aust J Rural Health 2001; 9 Suppl 1: S27-S31.

25 Woolley T, Sen Gupta TK, Thistlethwaite J. Effective and enthusiastic rural preceptors. What they need to know and what they need to have. Canberra: Department of Health and Ageing, 2005.

26 Nichols A, Worley P, Toms L, Johnston-Smith PR. Change of place, change of pace, change of status: rural community training for junior doctors, does it influence choices of training and career? Rural Remote Health 2004; 4: 259.

27 Young L, Johnston-Smith P. PGPPP: an opportunity to experience general practice [abstract]. Coasting to Gold14th National Prevocational Medical Education Forum; 2009 Nov 15-18; Surfers Paradise, Queensland.

28 Young L, Johnston-Smith P. Junior doctors develop primary healthcare skills in Indigenous communities [abstract]. Australian General Practice Network National Forum; 2009 Nov 9-12; Sydney, New South Wales.

29 Hesketh EA, Allan MS, Harden RM, Macpherson SG. New doctors' perceptions of their educational development during their first year of postgraduate training. Med Teach 2003; 25: 67-76.

30 Hewitt N, McKinstry B, Wilton J. Pre-registration house officers in general practice: a report on the experience in South East Scotland 1998-99. Educ Prim Care 2001; 12: 185-192.

31 Mak DB, Plant AJ, Toussaint S. “I have learnt ... a different way of looking at people's health": an evaluation of a prevocational medical training program in public health medicine and primary health care in remote Australia. Med Teach 2006; 28: el49-el55.

32 Martin AA, Laurence CO, Black LE, Mugford BV. General practice placements for pre-registration junior doctors: adding value to intern education and training. Med J Aust 2007; 186: 346-349.

33 Williams C, Cantillon P, Cochrane M. The clinical and educational experiences of pre-registration house officers in general practice. Med Educ 2001; 35: 774-781.

34 Crotty BJ, Brown T. An urgent challenge: new training opportunities for junior medical officers. Med J Aust 2007; 186 (7Suppl): S25-S27.

35 Sen Gupta TK, Murray RB, Beaton NS, et al. A tale of three hospitals: solving learning and workforce needs together. Med J Aust 2009; 191: 105-109. 